\title{
Impact of immune system stimulation on the ileal nutrient digestibility and utilisation of methionine plus cysteine intake for whole-body protein deposition in growing pigs
}

\author{
Anoosh Rakhshandeh ${ }^{1,2}$, John K. Htoo ${ }^{3}$, Neil Karrow ${ }^{1}$, Stephen P. Miller ${ }^{1}$ and Cornelis F. M. de Lange ${ }^{1 *}$ \\ ${ }^{1}$ Department of Animal and Poultry Science, University of Guelph, 50 Stone Road West, Guelph, ON, Canada N1G 2W1 \\ ${ }^{2}$ Department of Animal and Food Sciences, Texas Tech University, Lubbock, TX 79409-2141, USA \\ ${ }^{3}$ Health and Nutrition, Evonik Degussa GmbH, Rodenbacher Chaussee 4, 63457 Hanau-Wolfgang, Germany \\ (Submitted 22 June 2012 - Final revision received 13 May 2013 - Accepted 18 May 2013 - First published online 27 June 2013)
}

\section{Abstract}

The impact of immune system stimulation (ISS) on the ileal nutrient digestibility and utilisation of dietary methionine plus cysteine (SAA) intake for whole-body protein deposition (PD) was evaluated in growing pigs. For this purpose, sixty barrows were used in two experiments: thirty-six pigs in Expt I and twenty-four pigs in Expt II. Pigs were feed restricted and assigned to five levels of dietary SAA allowance (three and two levels in Expt I and II, respectively) from SAA-limiting diets. Following adaptation, pigs at each dietary SAA level were injected with either increasing amounts of Escherichia coli lipopolysaccharide (ISS+; eight and six pigs per dietary SAA level in Expt I and II, respectively) or saline (ISS - ; four and six pigs in Expt I and II, respectively) while measuring the whole-body nitrogen $(\mathrm{N})$ balance. After N-balance observations, pigs were euthanised, organs were removed and ileal digesta were collected for determining nutrient digestibility. Ileal digestibility of gross energy, crude protein and amino acids was not affected by ISS $(P>0 \cdot 20)$. ISS reduced PD at all levels of dietary SAA intake $(P<0 \cdot 01)$. The linear relationship between daily dietary SAA intake and PD observed at the three lowest dietary SAA intake levels indicated that ISS increased extrapolated maintenance SAA requirements $(P<0.05)$, but had no effect on the partial efficiency of the utilisation of dietary SAA intake for PD $(P>0 \cdot 20)$. Physiological and metabolic changes associated with systemic ISS had no effect on the ileal digestibility of nutrients per se, but altered SAA requirements for PD in growing pigs.

Key words: Immune system stimulation: Sulphur amino acids: Ileal nutrient digestibility: Protein deposition

It is well established that immune system stimulation (ISS) alters protein and amino acid (AA) metabolism and utilisation in animals and humans ${ }^{(1)}$. During ISS, AA are redirected from growth and reproduction towards mounting an immune response, which influences AA requirements ${ }^{(2)}$. The latter may contribute to additional muscle proteolysis. Glutamine, arginine, aromatic AA, threonine, methionine and cysteine (Cys) putatively become more critical relative to other AA during ISS ${ }^{(1,2)}$.

Special attention has been given to the metabolism of methionine and Cys (sulphur amino acids; SAA) during ISS due to their role as precursors for the synthesis of proteins and metabolites that are involved in the immune response ${ }^{(3)}$. About half of the Cys flux in healthy adults and rats can be accounted for by the synthesis of glutathione (GSH), while the remainder is used primarily for protein synthesis ${ }^{(4,5)}$. It has been shown in rats that Cys flux increases substantially during disease due to enhanced GSH turnover ${ }^{(3,6)}$. Moreover, Malmezat et al. ${ }^{(6)}$ observed a fourfold increase in metabolic demand for Cys in septic rats due to an increased synthesis of GSH. An increase in erythrocyte GSH synthesis rate during ISS has also been observed in pigs and human subjects $^{(7)}$. Furthermore, Cys is required for the synthesis of Cys-rich defensins, antimicrobial peptides and the acutephase protein albumin, the synthesis of which increases substantially during ISS $^{(8,9)}$. Increases in methionine metabolism (i.e. transmethylation and remethylation) have been observed in patients with systemic inflammation, as a result of increased methyl group utilisation for the synthesis of polyamines, choline and carnitine ${ }^{(10)}$. These observations indicate enhanced metabolic demands for SAA during ISS. However, quantitative estimates of the impact of ISS on dietary SAA requirements in animals for optimum biological performance have not been generated.

Abbreviations: AA, amino acid; AID, apparent ileal digestibility; BW, body weight; CP, crude protein; Cys, cysteine; GSH, glutathione; ISS, immune system stimulation; LPS, lipopolysaccharide; PD, protein deposition; SAA, sulphur amino acids; SID, standardised ileal digestibility.

*Corresponding author: C. F. M. de Lange, fax +1 5198369873 , email cdelange@uoguelph.ca 
The gastrointestinal tract is also involved in defence activities during ISS. This involvement results in morphological and physiological changes, including oedema, as well as changes in gut motility, permeability, microflora ${ }^{(11)}$, expression of digestive enzymes $^{(12)}$, mucin production ${ }^{(13)}$ and epithelial transport systems $^{(14)}$. However, little is known about the impact of ISS on the measures of nutrient digestibility.

Therefore, in the present study, two experiments were conducted to determine the effect of chronic ISS on ileal nutrient digestibility and utilisation of SAA intake for whole-body protein deposition (PD) in growing pigs.

\section{Materials and methods}

\section{General procedures}

Institutional and national guidelines for the care and use of animals were followed, and all experimental procedures were reviewed and approved by the University of Guelph Animal Care Committee. In two experiments (Expt I and II), a total of sixty Yorkshire barrows were obtained from the University of Guelph Arkell Swine Research Center (Arkell, ON, Canada), housed individually in metabolism crates, as described by Nyachoti et al. ${ }^{(15)}$. Across the two experiments, pigs were subjected to five different levels of dietary SAA that were lower than the established SAA requirements ${ }^{(16)}$.
Pigs were allowed to acclimatise to environmental conditions for $10 \mathrm{~d}$. During the first $3 \mathrm{~d}$ of the acclimatisation period, pigs were fed ad libitum on a commercial swine starter diet. Pigs were then assigned to experimental diets and feed restricted to approximately $38 \mathrm{~g} \mathrm{DM} / \mathrm{kg}$ body weight (BW) per $\mathrm{d}$. The $\mathrm{N}$-balance method was used to establish the PD of individual pigs before and during ISS. At the end of the experiment, pigs were euthanised by an intravenous injection of sodium pentobarbital (0.3 mg/kg BW; Virbac AH).

\section{Treatments, experimental design, diets and feeding}

Experiment I. A total of thirty-six barrows (initial BW 18.6 (SE 0.70$) \mathrm{kg}$ ) were blocked by time in two equal groups of eighteen pigs and randomly assigned to dietary treatments. Dietary treatments were arranged in a $3 \times 2$ factorial randomised complete block design with two main factors: (1) three levels of dietary SAA allowance $(1.0,2.4$ or $3.6 \mathrm{~g} / \mathrm{d}$, representing 15,37 and 55\%, respectively, of established SAA requirements for maximum growth for pigs of this $\mathrm{BW}^{(16)}$ ) and (2) ISS (ISS $-v$. ISS+). A total of three soya protein isolate and maize starch-based diets were formulated, in which SAA were among the first-limiting AA (diets 1 to 3; Table 1). The dietary SAA levels were achieved by altering the ratio of maize starch:soya protein isolate, which contains

Table 1. Ingredient composition and analysed nutrient contents of the experimental diets

\begin{tabular}{|c|c|c|c|c|c|}
\hline & \multicolumn{5}{|c|}{ Dietary treatments } \\
\hline & \multicolumn{3}{|c|}{ Expt I } & \multicolumn{2}{|c|}{ Expt II } \\
\hline & 1 & 2 & 3 & 4 & 5 \\
\hline \multicolumn{6}{|l|}{ Ingredient composition (g/kg, as-fed basis) } \\
\hline Maize starch & 620 & 544 & 469 & 495 & 369 \\
\hline Cellulose & 40 & 40 & 40 & 40 & 40 \\
\hline Soyabean meal & - & - & - & 307 & 440 \\
\hline Soya protein concentrate ( $64 \%$ protein) & 70 & 148 & 224 & - & - \\
\hline Sucrose & 150 & 150 & 150 & 80 & 80 \\
\hline Animal-vegetable fat blend & 70 & 70 & 70 & 60 & 60 \\
\hline Limestone & 18 & 17 & 17 & 10 & 9 \\
\hline Dicalcium phosphate & 20 & 19 & 18 & 14 & 13 \\
\hline Salt ( $\mathrm{NaCl})$ & 5 & 5 & 5 & 5 & 5 \\
\hline Magnesium sulphate & 2 & 1 & - & - & - \\
\hline Vitamin and mineral premix* & 6 & 6 & 6 & 6 & 6 \\
\hline Titanium dioxide & 1 & 1 & 1 & 1 & 1 \\
\hline \multicolumn{6}{|l|}{ Analysed nutrient content (g/kg DM) } \\
\hline DM & 934 & 923 & 934 & 920 & 923 \\
\hline Metabolisable energy $\dagger$ & $15 \cdot 0$ & $15 \cdot 0$ & $15 \cdot 0$ & $15 \cdot 0$ & $15 \cdot 0$ \\
\hline Crude protein $(\mathrm{N} \times 6.25)$ & $64 \cdot 0$ & $111 \cdot 0$ & $161 \cdot 0$ & $181 \cdot 8$ & 214.6 \\
\hline Lys & $3 \cdot 10$ & $7 \cdot 20$ & $10 \cdot 2$ & 9.60 & $10 \cdot 6$ \\
\hline Met & 0.70 & 1.50 & $2 \cdot 10$ & $2 \cdot 30$ & $2 \cdot 80$ \\
\hline Met + Cys (SAA) & 1.30 & 2.90 & $4 \cdot 20$ & 4.60 & 5.90 \\
\hline Thr & 2.00 & 4.50 & $6 \cdot 40$ & $7 \cdot 30$ & $8 \cdot 70$ \\
\hline Arg & $3 \cdot 70$ & 8.50 & $12 \cdot 3$ & 13.9 & $15 \cdot 5$ \\
\hline Leu & 4.00 & $9 \cdot 00$ & $12 \cdot 9$ & $14 \cdot 2$ & $16 \cdot 2$ \\
\hline Ile & $2 \cdot 10$ & $5 \cdot 20$ & 7.50 & 8.70 & $9 \cdot 70$ \\
\hline \multicolumn{6}{|c|}{ 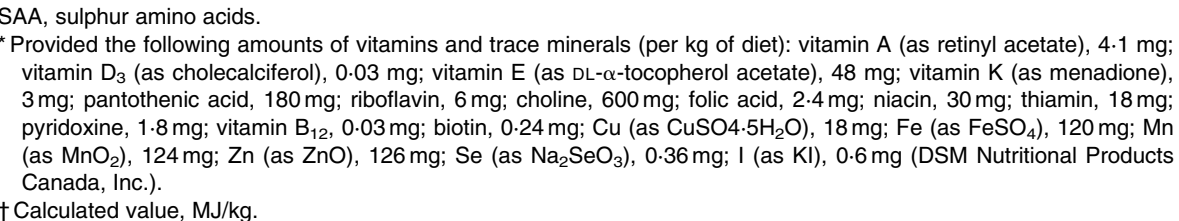 } \\
\hline
\end{tabular}


relatively low levels of SAA (Table 1). The ratios of essential AA:SAA in soya protein exceed the recommendations given by Wang \& Fuller ${ }^{(17)}$ and the National Research Council ${ }^{(16)}$ by $20 \%$ (Table 1 ). The diets were calculated to contain $5.0 \mathrm{MJ} / \mathrm{kg}$ of metabolisable energy. The diets were fortified with vitamins and minerals to surpass the requirements recommended by the National Research Council (Table 1) ${ }^{(16)}$. Titanium dioxide $\left(0 \cdot 1 \% \mathrm{TiO}_{2} ;\right.$ Sigma-Aldrich Limited) was included in all the diets as an indigestible marker for determining ileal digestibility of nutrients. Pigs were fed equal meals twice per d at 08.00 and 16.00 hours. Daily feed allowance was restricted to $800 \mathrm{~g} / \mathrm{d}$, resulting in daily metabolisable energy intakes of $12.0 \mathrm{MJ} / \mathrm{d}$, to ensure constant energy intake levels across all the dietary treatments. Water intake was restricted to 2.5 litres/d to avoid water spillage and contamination of urine. A $5 \mathrm{~d}$ pre-ISS $\mathrm{N}$ balance was conducted to establish the PD of individual pigs as influenced by the SAA intake levels ( $n$ 12). At the end of the pre-ISS N-balance period, pigs at each SAA dietary level were injected intramuscularly with either lipopolysaccharide (LPS) ( $n$ 8; ISS+) or the same volume of a sterile saline solution ( $n$ 4; ISS - ). ISS was induced by an intramuscular repeated injection of increasing doses of Escherichia coli LPS every $48 \mathrm{~h}$ for $7 \mathrm{~d}$. The initial dosage of $60 \mu \mathrm{g} / \mathrm{kg}$ BW was increased by $12 \%$ at subsequent injections to avoid LPS tolerance ${ }^{(18)}$. Subsequently, two consecutive N-balances (lasting 3 and $4 \mathrm{~d}$, respectively) were conducted to monitor the pattern of PD during ISS.

Experiment II. A total of twenty-four barrows (initial BW 23.4 (SE 0.43$) \mathrm{kg}$ ) were blocked by time in two equal groups of twelve pigs and randomly assigned to dietary treatments. Dietary treatments were arranged in a $2 \times 2$ factorial randomised complete block design with the following factors: (1) two levels of dietary SAA allowance $(4.0$ or $5.0 \mathrm{~g} / \mathrm{d}$, representing 61 and $77 \%$, respectively, of established SAA requirements for maximum growth for pigs of this $\mathrm{BW}^{(16)}$ and (2) ISS (ISS $-v$. ISS + ). Compositions of the experimental diets are presented in Table 1 (diets 4 and 5). The same principles were used for diet formulation as in Expt I, with the exception of using a soyabean meal as the sole source of dietary AA in Expt II. As per Expt I, a 5d pre-ISS N-balance period ( $n 12$ at each dietary SAA level) was followed by two N-balance periods during ISS. At the end of the first N-balance period, half of the pigs ( $n$ 6) at each dietary SAA level were injected intramuscularly with either LPS or the same volume of a saline solution, as described in Expt I.

\section{Observations and sampling}

Body weight and body temperature. BW was measured at the beginning and end of each N-balance period. Eye temperature (Expt I) or rectal temperature (Expt II) was monitored daily. Thermography of eye was performed using an IR camera (ThermaCam ${ }^{\text {TM }}$ SC2000; FLIRSystems, Inc. ${ }^{(19,20)}$ ). The camera was calibrated each day for room temperature and relative humidity ${ }^{(19)}$. The emissivity value was set at 0.98 according to the camera manufacturer's recommendation for biological tissues. Multiple IR pictures were taken approximately $0.8 \mathrm{~m}$ from the right eye and the best pictures, in terms of focus and precision, were selected for interpretation. The IR pictures were interpreted using ThermaCam ${ }^{\mathrm{TM}}$ Researcher 2001 software (FLIR Systems AB). An average of the best three pictures was taken and used for further analysis and interpretation. Due to the unavailability of the IR camera in Expt II, rectal temperature was measured ${ }^{(20)}$.

Nitrogen balance. Urine was collected quantitatively and sampled daily as described by Zhu et $a l^{(21)}$. Urine was collected in tared bottles, containing a sufficient amount of $5 \mathrm{M}-\mathrm{HCl}$ to maintain a $\mathrm{pH}$ below $2 \cdot 5$. Faeces were collected twice daily and stored in sealed plastic bags at $-20^{\circ} \mathrm{C}$ until further processing. At the end of each N-balance period, faeces were thawed, pooled for each pig, homogenised using a Hobart mixer (Hobart Corporation) and kept in sealed plastic bags at $-20^{\circ} \mathrm{C}$ until further processing. Wasted feed, including vomit, was collected quantitatively using feed wastage trays, pooled for each pig and N-balance period, oven dried at $60^{\circ} \mathrm{C}$, left overnight and then weighed to derive the actual daily $\mathrm{N}$ intake.

Blood collection and processing. Blood samples were taken by retro-orbital sinus bleeding at the end of the last N-balance period. For complete blood cell counts, blood was collected in tubes containing EDTA (BD Vacutainer; BD) kept on ice and analysed within $2 \mathrm{~h}$ after collection. For measuring serum albumin and haptoglobin levels, blood samples were collected in a serum tube containing clot activator (BD Vacutainer), left at room temperature for $1 \mathrm{~h}$, centrifuged at $1500 \mathrm{~g}$ and stored at $-20^{\circ} \mathrm{C}$. For determining plasma fibrinogen levels, blood samples was collected in tubes containing sodium citrate (BD Vacutainer), centrifuged immediately for $10 \mathrm{~min}$ at $1500 \mathrm{~g}$ at $4^{\circ} \mathrm{C}$ and stored at $-20^{\circ} \mathrm{C}$.

Apparent ileal digestibility of nutrients and organ weights. The slaughter technique was used to measure the apparent ileal digestibility (AID) of nutrients ${ }^{(22)}$. Between 6 and $7 \mathrm{~h}$, after the morning meal and immediately after euthanasia, a ventral abdominal incision was made, spleen and liver were removed, rinsed with physiological saline, blotted dry and weighed. The last $100 \mathrm{~cm}$ of the small intestine was then isolated and clamped to prevent digesta movement. The ileum was then excised and the ileal digesta were gently expelled, collected and stored at $-20^{\circ} \mathrm{C}$ until further processing.

Chemical analysis. Blood levels of acute-phase proteins and complete blood cell counts were determined at the Animal Health Laboratory of the University of Guelph. Serum albumin and haptoglobin levels were analysed using a Roche cobas c501 biochemistry analyser (Roche Diagnostics $)^{(23,24)}$. Plasma fibrinogen was quantified using a KC4 Delta semi-automatic coagulation analyser (Trinity Biotech) and a TirinitClot kit (TriniCLOT ${ }^{\mathrm{TM}}$ Fibrinogen; Trinity Biotech). Complete blood count was performed using the ADIVA 120 Hematology System (Siemens Healthcare Diagnostics, Inc.).

Faecal samples along with ileal digesta and dietary samples were freeze-dried, ground and thoroughly mixed before analysis. $\mathrm{TiO}_{2}$ and $\mathrm{DM}$ were determined according to the standard Association of Official Analytical Chemists procedures ${ }^{(25)}$ $\mathrm{N}$ contents of the faeces and urine were measured using a LECO FP-428 Nitrogen Determinator combustion instrument (LECO Corporation) and analysed according to the standard 
Association of Official Analytical Chemists procedures ${ }^{(25)}$. Ileal digesta and dietary $\mathrm{N}$ contents were determined by LECO FP-2000 (LECO Corporation) at the laboratory of Evonik Degussa $\mathrm{GmbH}$. Gross energy of the dietary and ileal digesta samples was determined as suggested by Widyaratne \& Zijlstra $^{(26)}$ using an IKA oxygen bomb calorimeter (model C 5003; IKA GmbH \& Company KG).

$\mathrm{AA}$ analyses of the feed and digesta samples were performed at the laboratory of Evonik Degussa GmbH. AA contents in the dietary and ileal digesta samples were determined by ion-exchange chromatography with post-column derivatisation with ninhydrin. Before protein hydrolyses, AA were oxidised with performic acid, which was neutralised with sodium metabisulphite ${ }^{(27)}$. The samples were hydrolysed with $6 \mathrm{M}-\mathrm{HCl}$ for $24 \mathrm{~h}$ at $110^{\circ} \mathrm{C}$. AA were quantified with the internal standard method by measuring the absorption of reaction products with ninhydrin at $570 \mathrm{~nm}$.

\section{Calculation and statistical analyses}

Calculations. The AID of crude protein (CP; N $\times 6.25)$, AA and gross energy were calculated using the indicator method and $\mathrm{TiO}_{2}$ as an indigestible marker. Standardised ileal digestibility (SID) of AA was estimated as described by Stein et al. ${ }^{(28)}$. The basal endogenous loss of each AA was calculated using the profile of basal endogenous AA in growing pigs as described by Jansman et al. ${ }^{(29)}$.

SID SAA intake was calculated as follows:

$$
\text { SID SAA intake }(\mathrm{g} / \mathrm{d})=(\operatorname{SID} \text { SAA } / 100) \times\left(\mathrm{SAA}_{\text {diet }} \times \mathrm{DMI}\right),
$$

where SID SAA is the SID of SAA (\%) and SAA diet and DMI are dietary SAA contents $(\mathrm{g} / \mathrm{kg} \mathrm{DM})$ and $\mathrm{DM}$ intake $(\mathrm{kg} / \mathrm{d})$, respectively.

Whole-body PD $(\mathrm{N}$ retention $\times 6.25)$ was calculated as described by $\mathrm{Zhu}$ et $a{ }^{(21)}$. Faecal protein digestibility was measured, using $\mathrm{TiO}_{2}$ as an indigestible marker, to compute faecal $\mathrm{N}$ excretion from dietary $\mathrm{N}$ intake.

Linear-plateau (broken-line) regression models were used to relate PD $(\mathrm{g} / \mathrm{d})$ to SID SAA intake $(\mathrm{g} / \mathrm{d})$ and to estimate the cross-over point of dietary SAA intakes required to just reach plateau or maximum PD in ISS+ and ISS - pigs $^{(30)}$.

At dietary SAA intakes below the cross-over point, the following linear regression model was used to estimate maintenance SID SAA requirements and the partial efficiency of SAA utilisation for PD:

$$
\operatorname{PD}(\mathrm{g} / \mathrm{d})=a+b \times(\text { SID SAA intake }) .
$$

The regression coefficients $a$ and $b$ were used to estimate maintenance SID SAA requirements $(\mathrm{g} / \mathrm{d})$, i.e. SID AA intake when PD equals zero, calculated as $-a / b$. The regression coefficient $b$ (g PD/g SID SAA intake) represents the partial efficiency of the utilisation of SID SAA intake for PD ${ }^{(31)}$.

Statistical analyses. Statistical analyses were carried out using SAS software version 9.1 (SAS Institute, Inc.). One-time observations such as final BW, organ weights, plasma acutephase protein concentrations and measures of digestibility were analysed using a factorial randomised complete block design (PROC MIXED) with dietary SAA allowance (D; three and two levels in Expt I and II, respectively), ISS (ISS$v$. ISS + ), interaction between $\mathrm{D}$ and ISS $(\mathrm{D} \times \mathrm{ISS})$ and group of pigs (block) as fixed effects and pig within D and ISS as the random effect. Results for body temperature, PD and SID SAA intake were analysed separately for the two experiments as repeated measurements across the N-balance periods in a factorial randomised complete block design. This model included D, ISS, D $\times$ ISS, N-balance periods and block as fixed effects and pig within D and ISS as the random effect. Due to the sequential nature of the observations on each animal, a compound symmetry structure that yielded the model with the best fit was identified, according to the Akaike and Bayesian information criteria ${ }^{(32)}$. Values are reported as least-square means with their standard errors. The differences in the efficiency of SAA utilisation for PD (slopes) as well as SAA requirements for maintenance between the ISS - and ISS+ pigs were tested using the regression procedure (PROC REG). Treatment effects were considered significant at $P \leq 0 \cdot 05$. A tendency towards a significant difference between treatment means was also considered at $P \leq 0 \cdot 10$.

\section{Results}

\section{General observations}

Pigs readily consumed the experimental diets. The ISS+ pigs displayed some clinical signs of disease such as lethargy, vomiting and mild skin rashes. DM from vomit and wasted feed was less than $2.0 \%$ of feed allowance. The analysed

Table 2. Impact of immune system stimulation (ISS) on the relative weight of organs, body temperature, levels of acute-phase proteins and blood cell counts*

\begin{tabular}{|c|c|c|c|c|}
\hline & ISS- & ISS+ & SE & $P$ \\
\hline \multicolumn{5}{|l|}{ Organ weight (\% BW) } \\
\hline Liver $_{\text {Expt I }}$ & $2 \cdot 76$ & $3 \cdot 02$ & 0.08 & 0.01 \\
\hline Spleen $_{\text {Expt I }}$ & 0.17 & $0 \cdot 27$ & 0.01 & 0.01 \\
\hline Liver $_{\text {Expt II }}$ & $2 \cdot 34$ & $2 \cdot 80$ & 0.09 & 0.01 \\
\hline \multicolumn{5}{|l|}{ Body temperature $\left({ }^{\circ} \mathrm{C}\right)$} \\
\hline Eye $_{\text {Expt I }} \dagger$ & $36 \cdot 3$ & $37 \cdot 5$ & 0.10 & 0.01 \\
\hline Rectal $_{\text {Expt ॥}} \dagger$ & $39 \cdot 8$ & $40 \cdot 2$ & 0.07 & 0.05 \\
\hline \multicolumn{5}{|l|}{ Acute-phase proteins $(\mathrm{g} / \mathrm{l})$} \\
\hline Serum albumin $_{\text {Expt I }}$ & $30 \cdot 7$ & $30 \cdot 5$ & $1 \cdot 74$ & 0.93 \\
\hline Plasma fibrinogen $_{\text {Expt I }}$ & $1 \cdot 33$ & 1.76 & 0.16 & 0.04 \\
\hline Serum haptoglobin Expt I & $1 \cdot 83$ & $3 \cdot 87$ & 0.58 & 0.01 \\
\hline \multicolumn{5}{|l|}{ Blood cell count Expt I } \\
\hline Leucocytes $\left(\times 10^{9} / \mathrm{I}\right)$ & $24 \cdot 1$ & $40 \cdot 2$ & $3 \cdot 39$ & 0.01 \\
\hline Erythrocytes $\left(\times 10^{12} / \mathrm{I}\right)$ & $7 \cdot 85$ & $7 \cdot 20$ & 0.25 & 0.12 \\
\hline $\mathrm{Hb}(\mathrm{g} / \mathrm{l})$ & 131 & 127 & $5 \cdot 00$ & 0.52 \\
\hline Haematocrit (I/I) & 0.37 & 0.37 & 0.03 & 0.89 \\
\hline
\end{tabular}

(Least-square means with their standard errors)

BW, body weight.

${ }^{*}$ Data are least-square means and represent the data obtained on day 7 after the start of ISS. Twenty-four out of thirty-six pigs in Expt I and twelve out of twentyfour pigs in Expt II were injected (intramuscularly) every $48 \mathrm{~h}$ over a $7 \mathrm{~d}$ period with increasing amounts of lipopolysaccharide (ISS + ). The remaining pigs were injected with a sterile saline solution (ISS-). In both experiments, responses were not influenced by the dietary treatments and there were no interaction effects of ISS $\times$ dietary treatment. Therefore, the results were pooled across the dietary treatments.

† Mean values of the $7 \mathrm{~d}$ period during ISS and based on the repeated-measures ANOVA. 


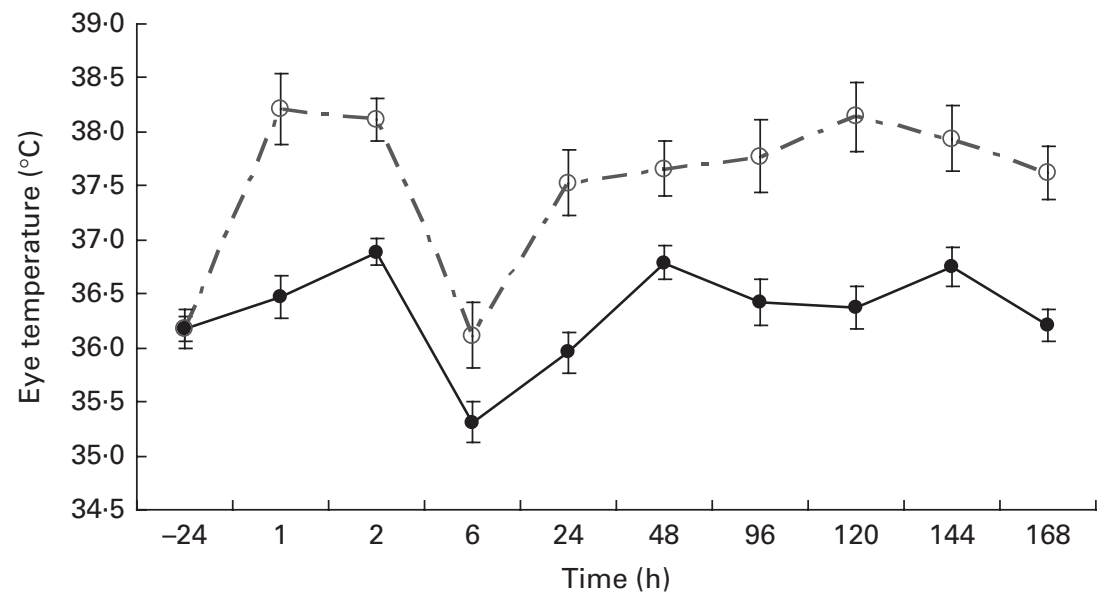

Fig. 1. Impact of immune system stimulation (ISS) on the eye temperature of growing pigs during the $7 \mathrm{~d}$ ISS period (Expt I). Twenty-four out of thirty-six pigs were injected (intramuscularly) every $48 \mathrm{~h}$ for $7 \mathrm{~d}$ with increasing amounts of lipopolysaccharide (ISS,$\left.+-_{-}\right)$. The remaining pigs ( $n$ 12) were injected with a sterile saline solution (ISS - , - -). Eye temperature was determined by performing thermography of the eye using IR imaging.

dietary nutrient contents were generally in agreement with anticipated values $( \pm 10 \%)$ that were derived from feed ingredient composition and nutrient levels in feed ingredients according to the National Research Council ${ }^{(16)}$. Only for diet 4 (Expt 2), the analysed $\mathrm{CP}$ and AA contents were higher than the anticipated values $(>15 \%)$. For the interpretation of the results, the analysed dietary nutrient contents and the observed AA digestibility values were used.

\section{Measures of immune function}

No interaction effects of $\mathrm{D} \times$ ISS or effects of $\mathrm{D}$ on the measures of immune function were observed $(P>0 \cdot 10$; Table 2). Repeated injection with increasing amounts of LPS increased the relative weights of spleen in Expt I and liver in Expt I and II $(P<0 \cdot 01)$, as well as the eye (Expt I; Fig. 1) and rectal (Expt II) temperatures, by 1.2 and $0.4^{\circ} \mathrm{C}$, respectively $(P<0.05)$. Plasma levels of haptoglobin and fibrinogen were also increased as a result of ISS (Expt I; $P<0 \cdot 04$ ). No treatment effect on serum albumin levels was observed $(P>0 \cdot 10)$. ISS increased leucocyte counts $(P<0 \cdot 05)$, but had no effect on erythrocyte counts, $\mathrm{Hb}$ or haematocrit levels in Expt I $(P>0 \cdot 10)$

\section{Nutrient digestibility}

In both Expt I and II, no effects of D or interaction effects of ISS $\times \mathrm{D}$ on the AID of energy or the SID of CP and AA were observed ( $P>0 \cdot 10$; Table 3 ). Neither the AID of gross energy (measured only in Expt I), nor the SID of CP and key AA (i.e. essential AA that are among the first-limiting AA in practical pig diets) was affected by ISS (Table $3 ; P>0 \cdot 20$ ).

Table 3. Impact of immune system stimulation (ISS) on the apparent ileal digestibility (\%, AID) of energy and standardised ileal digestibility (\%, SID) of crude protein and some amino acids*

(Least-square means with their standard errors)

\begin{tabular}{|c|c|c|c|c|c|c|}
\hline \multirow[b]{2}{*}{ Nutrients } & \multicolumn{3}{|c|}{ Expt I† } & \multicolumn{3}{|c|}{ Expt II† } \\
\hline & ISS- & ISS+ & SE & ISS- & ISS+ & SE \\
\hline Energy & 83.6 & 83.5 & 1.74 & - & - & - \\
\hline Protein & 80.5 & $78 \cdot 0$ & $4 \cdot 10$ & 80.6 & $76 \cdot 8$ & 3.44 \\
\hline Lys & $86 \cdot 8$ & 83.7 & $2 \cdot 26$ & $89 \cdot 1$ & $88 \cdot 0$ & 1.75 \\
\hline Met & $87 \cdot 8$ & $86 \cdot 0$ & 1.81 & $87 \cdot 8$ & $88 \cdot 1$ & 3.42 \\
\hline Met + Cys & $85 \cdot 0$ & 80.5 & 2.93 & $82 \cdot 7$ & $80 \cdot 6$ & 3.46 \\
\hline Thr & $83 \cdot 3$ & $77 \cdot 8$ & $3 \cdot 35$ & $79 \cdot 0$ & $76 \cdot 6$ & $5 \cdot 17$ \\
\hline Arg & 88.4 & $87 \cdot 7$ & 3.02 & 91.6 & 90.5 & 1.60 \\
\hline $\mathrm{lle}$ & $87 \cdot 6$ & 84.4 & $2 \cdot 35$ & 85.7 & $86 \cdot 0$ & 3.07 \\
\hline Leu & $86 \cdot 2$ & $83 \cdot 1$ & $1 \cdot 24$ & 83.0 & 83.6 & 3.86 \\
\hline \multicolumn{7}{|c|}{$\begin{array}{l}\text { * Data are least-square means and represent the data obtained on day } 7 \text { after the start of ISS. AID was determined } \\
\text { using an indigestible marker }\left(\mathrm{TiO}_{2}\right) \text { and the slaughter technique. SID was calculated as: AID \% }+\left(\left(\mathrm{basal} I A A_{\text {end }} /\right.\right. \\
\left.\left.A A_{\text {diet }}\right) \times 100\right) \text {. Basal IAA } A_{\text {end }} \text { represents the basal endogenous loss of an amino acid (AA) expressed as g/kg DM } \\
\text { intake as described by Jansman et al. }{ }^{(29)} \text { and } \mathrm{AA}_{\text {diet }} \text { is the AA content in the diet (g/kg DM). There were no statisti- } \\
\text { cally significant differences. } \\
\text { †Pigs in Expt I and II were fed a maize starch and soya protein concentrate-based diet and a maize starch and } \\
\text { soyabean meal-based diet, respectively. Twenty-four out of thirty-six pigs in Expt I and twelve out of twenty-four } \\
\text { pigs in Expt II were injected (intramuscularly) every } 48 \mathrm{~h} \text { for } 7 \mathrm{~d} \text { with increasing amounts of LPS (ISS }+ \text { ). The } \\
\text { remaining pigs were injected with a sterile saline solution (ISS-). The dietary treatments did not influence the SID } \\
\text { of amino acids and the AID of energy, and there were no interaction effects of ISS } \times \text { dietary treatments. Therefore, } \\
\text { the results were pooled across the dietary treatments. }\end{array}$} \\
\hline
\end{tabular}




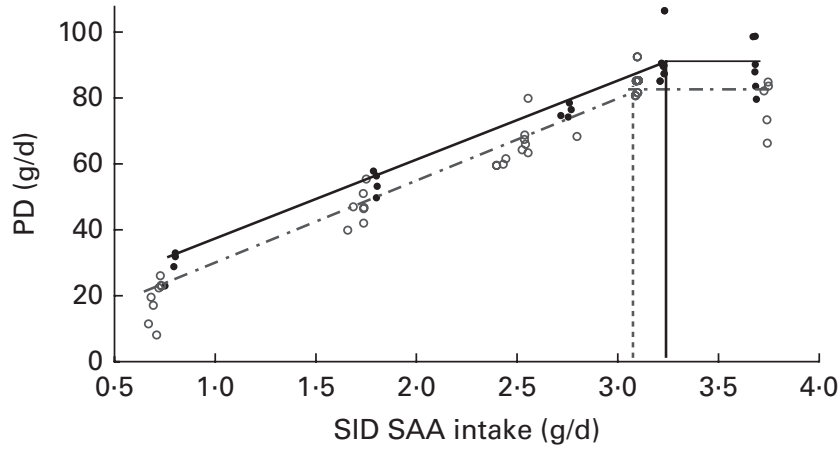

Fig. 2. Impact of immune system stimulation (ISS) and standardised ileal digestible (SID) methionine plus cysteine (SAA) intake on whole-body protein deposition (PD) in growing pigs. Results of the two experiments (Expt I and II) were combined for the linear-plateau regression analysis. Pigs in Expt I and II were fed a maize starch and soya protein concentrate-based diet, and a maize starch and soyabean meal-based diet, respectively. Three (1.0, 2.4 and $3.6 \mathrm{~g} / \mathrm{d})$ and two levels $(4.0$ and $5.0 \mathrm{~g} / \mathrm{d}$ ) of SAA intake were used in Expt I and II, respectively (see Tables 4 and 5). Twenty-four out of thirty-six pigs in Expt I and twelve out of twenty-four pigs in Expt II were injected (intramuscularly) every $48 \mathrm{~h}$ for $7 \mathrm{~d}$ with increasing amounts of lipopolysaccharide (ISS,$+--\circ)$. The remaining pigs were injected with a sterile saline solution $($ ISS,$--\infty)$

utilisation of SAA intake for PD. To our knowledge, this is the first attempt to evaluate SAA requirements and ileal digestibility of nutrients during ISS in growing pigs. In the present study, serial dilution of dietary protein sources was used to generate the dietary treatments and to avoid confounding of SAA intake levels with changes in dietary AA balance ${ }^{(33)}$. It has been shown that the efficiency of SAA utilisation for $\mathrm{PD}$ is affected by dietary AA balance ${ }^{(34)}$. In a previous study $^{(33)}$, it has been confirmed that SAA were among the first-limiting AA in the dietary AA profile that was used in the present study.

In an earlier study in our laboratory, we observed a persistent increase in plasma levels of cytokine IL-1 $\beta$ after repeated injection of pigs with increasing doses of LPS, which resulted in systemic inflammation ${ }^{(35,36)}$. Systemic inflammation leads to cell hypertrophy, and sometimes cell hyperplasia in organs that are involved in the immune response ${ }^{(37)}$. In the present study, ISS resulted in increased relative weights of liver and spleen, the two major organs that are involved in the immune response, which is in agreement with the findings of Breuille and others ${ }^{(6,38)}$. It has been suggested that a low nutrient intake compromises the immunocompetence of animals, including a reduced capability for maintaining plasma levels of acute-phase proteins ${ }^{(1,39)}$. However, in the present study, SID SAA intake had no effect on the plasma or serum levels of albumin, fibrinogen and haptoglobin, suggesting that production of acute-phase proteins has a high priority during ISS, even when AA intake is below the requirements for maximum PD.

The acute-phase response to ISS is characterised by fever, anorexia, reduced serum albumin levels and increased acute-phase plasma protein levels ${ }^{(40)}$. In the present study, repeated injection of pigs with LPS resulted in an increase in eye and rectal temperatures as well as plasma levels of haptoglobin and fibrinogen, the two major acute-phase proteins. However, we did not observe a reduction in serum albumin levels, which is inconsistent with the findings of Jahoor et $a{ }^{(39)}$, possibly due to the induction of only a relatively mild immune reaction in our ISS model. Moreover, ISS increased the leucocytes, which is one of the common clinical manifestations of the systemic inflammatory response ${ }^{(41-43)}$. Pro-inflammatory cytokines, such as IL-1, IL-6 and TNF- $\alpha$, as well as corticosteroids play an essential role in initiating the synthesis of hepatic acute-phase proteins and elevating body temperature; therefore, the increased plasma haptoglobin and fibrinogen levels as well as body temperature reflect ISS mediated by these molecules ${ }^{(35,43)}$. Collectively, these results indicate that the immune system was successfully stimulated in the present study.

It has been suggested that ISS induces morphological and functional changes in the gastrointestinal tract, which may perturb nutrient digestion and absorption ${ }^{(11,44)}$. However, this suggestion is not supported by experimental observations. In the present study, we measured the impact of ISS on the ileal digestibility of nutrients using a slaughter technique. We chose this technique to avoid additional stress caused by surgical procedures (e.g. cannulation), possible secondary infections and any interference with the digestive function of animals ${ }^{(45)}$. The impact of the three inherent technical problems with the slaughter method for measuring ileal nutrient digestibility was minimised by controlling the sampling time relative to the feeding schedule, clearly identifying the intestinal segment from which the samples were obtained, i.e. the distal ileum ${ }^{(46)}$, and minimising mucosal cell shedding by using sodium pentobarbital for euthanising the pigs ${ }^{(47)}$. In the present study, the observed AID AA and $\mathrm{CP}$ values were converted to SID AA and $\mathrm{CP}$ values by considering basal ileal endogenous losses, to correct for the known effects of dietary AA and CP levels on AID values ${ }^{(28)}$.

The SID of CP and AA were not affected by ISS in the present study, indicating that physiological changes in the gastrointestinal tract during LPS-induced ISS have minimal or no effect on overall digestive efficiency. Barker ${ }^{(48)}$ found

Table 6. Impact of immune system stimulation (ISS) on parameters representing the linear relationship between standardised ileal digestible (SID) sulphur amino acid (SAA) intake and protein deposition (PD) in growing pigs ${ }^{\star} \dagger$

(Least-square means with their standard errors)

\begin{tabular}{lcccc}
\hline & ISS - & ISS + & SE & $P \ddagger$ \\
\hline Intercept (PD at 0 SID SAA intake) & 8.75 & -0.54 & 3.9 & 0.02 \\
Slope (g PD/g SID SAA intake) & 25.3 & 27.1 & 1.2 & 0.27 \\
$R^{2}$ & 0.96 & 0.95 & - & - \\
\hline
\end{tabular}

${ }^{*}$ Results of the two experiments (Expt I and II) were combined for the linearplateau regression analysis (Fig. 2). Twenty-four out of thirty-six pigs in Expt I and twelve out of twenty-four pigs in Expt II were injected (intramuscularly) every $48 \mathrm{~h}$ for $7 \mathrm{~d}$ with increasing amounts of lipopolysaccharide (ISS + ). The remaining pigs were injected with a sterile saline solution (ISS-).

†One-slope model: $y=a+b(x)$, where $y$ is the PD $(\mathrm{g} / \mathrm{d}), a$ (intercept) can be used for mathematical estimation of extrapolated maintenance requirement $(-a / b)$, $b$ (slope) represents the partial efficiency of SAA utilisation for PD and $x$ is the daily SAA intake $(\mathrm{g} / \mathrm{d})$ when SAA intake is below the requirements for maximum $\mathrm{PD}$.

$\ddagger$ Significant differences among the dietary treatments. 
that an abnormal mucosa in ISS lambs was not associated with a reduction in feed efficiency and growth performance. Williams et $a l^{(49)}$ reported that apparent faecal digestibility of CP was not affected by ISS in growing pigs at different stages of growth. Similar results were also observed in a study with Actinobacillus pleuropneumoniae-challenged pigs ${ }^{(50)}$. It remains possible that ISS-induced reductions in feed intake have an impact on the measures of digestibility; in the present study, feed allowance was controlled and DMI was similar in pigs on ISS - and ISS $+{ }^{(51)}$. It should be mentioned that in the present study, the digestibility values were numerically lower and appeared to be more variable in the ISS+ animals than in the ISS - animals. This could be due to either increased endogenous gut protein and AA losses induced by ISS or to a reduction in absorptive capacity $^{(13,28)}$. Therefore, the impact of ISS on gut-specific endogenous losses and nutrient digestibility deserves further investigation. Reduced SID SAA intake in the ISS+ pigs in Expt I could be attributed to numerically lower SID values in the ISS+ animals and to some extent to the increased feed wastage and vomiting. The interaction effect of ISS $\times$ dietary treatment on SID SAA intake in Expt I could be linked mainly to numeric differences in DMI among the dietary treatments due to feed wastage and vomiting, especially for pigs on diets 1 and 3 .

Based on the assumption that SID SAA intakes represent available AA intakes that are independent of dietary AA sources, PD responses to the dietary treatments were combined across the two experiments for the ISS - and ISS+ pigs (Fig. 2). In the present study, plateau or maximum PD (Fig. 2) was reached for both ISS - and ISS+ pigs at the two highest dietary SAA intake levels. In the ISS - pigs, the plateau PD appears to be determined by the level of energy intake as a result of the restriction in feed intake ${ }^{(52)}$. The observed reduction in plateau PD in the ISS+ pigs is probably the result of a higher pro-inflammatory cytokine release and its associated endocrine changes ${ }^{(39,53)}$. Pro-inflammatory cytokines inhibit the release of anabolic hormones (e.g. somatotropin and insulin-like growth factor I) and increase protein degradation in skeletal muscles by activating the catabolic pathways, mainly through the ubiquitin-proteasome pathway $^{(49,53)}$.

Based on the linear-plateau regression models, SID SAA requirement for maximum $\mathrm{PD}$ in the ISS+ pigs was $8 \%$ lower than that in the ISS - pigs. The reduced requirements for SAA in the ISS+ pigs can be attributed largely to the reduced maximum PD in the ISS + pigs $^{(49)}$. It has been demonstrated that the efficiency of the utilisation of the firstlimiting AA for PD is reduced at the levels required for maximum $\mathrm{PD}^{(49,52)}$. Therefore, the marginal efficiency of the utilisation of SID SAA intake for PD was evaluated at the levels of SAA intake that are below the levels needed to maximise PD. In the present study, the marginal efficiency of the utilisation of SID SAA for PD was similar for the ISS+ and ISS - pigs; $1 \mathrm{~g}$ of additional SID SAA intake supported $25 \cdot 3$ (SE 1.26$) \mathrm{g} / \mathrm{d}$ for PD in the ISS - pigs and $27 \cdot 1$ (SE $1 \cdot 10) \mathrm{g} / \mathrm{d}$ in the ISS+ pigs, which is in agreement with N-balance observations reported by Fuller et al. ${ }^{(54)}$. Assuming that PD contains $3 \cdot 6 \%$
SAA and is similar for the ISS + and ISS - pigs, the mean efficiency of the utilisation of SID SAA intake for SAA retention in PD can be estimated at 0.94 in the present study ${ }^{(16)}$. This value is somewhat higher than previous estimates ${ }^{(16)}$, and reflects the systematic overestimation of PD values that are established using conventional N-balance methodology ${ }^{(54)}$. The assumption that PD in ISS - and ISS+ pigs contains the same amount of SAA may be questioned. We demonstrated previously that the whole-body sulphur content of pigs increases during ISS ${ }^{(55)}$. Larsson et al. ${ }^{(56)}$ reported that $\mathrm{N}$ excretion was enhanced to a greater extent than sulphur excretion (end product of SAA metabolism) in patients with systemic inflammation. Moreover, a study with TNF- $\alpha$-treated rats has shown a reduction in urinary inorganic sulphate and total sulphur excretion ${ }^{(57)}$. These observations have suggested that the whole-body SAA content increases relative to other AA during ISS, which can be attributed to the preferential retention of SAA, specifically Cys, in non-protein nitrogenous compounds such as $\mathrm{GSH}^{(5,55,58)}$.

SAA requirements of growing pigs can be divided into two main components: requirements for body maintenance functions and a requirement for $\mathrm{PD}^{(16)}$. The present study yields negative estimates of SID SAA requirements for maintenance in the ISS - pigs. The negative values can be attributed to the systematic bias when using N-balance methodology for measuring $\mathrm{PD}$ and the required extrapolation of the relationship between PD and SAA intakes to zero PD ${ }^{(52)}$. However, a higher estimate of maintenance SID SAA requirements in the ISS+ pigs than in the ISS - pigs (300 (SE 3.8) $\mathrm{mg} / \mathrm{d}$; using a common partial efficiency of SAA utilisation of $26 \cdot 2$ (SE 1.18) for the ISS - and ISS+ pigs; average coefficients $b$ in Table 6) directly contributes to the observed impact of ISS on PD at all the levels of dietary SAA intake. Maintenance requirements for absorbed SAA serves to replace endogenous gut and integument protein losses, replace SAA losses due to the minimum SAA catabolism and obligatory use for homeostasis of non-protein compounds such as $\mathrm{GSH}^{(31,54)}$. In pigs, integument protein losses are only a minor contributor to SAA requirements, and the present study suggests that there is no incremental effect of ISS on endogenous gut SAA losses ${ }^{(54)}$. Moreover, studies with human subjects and rats have shown that the rate of SAA catabolism remains unchanged or is reduced during ISS ${ }^{(59)}$. Therefore, it appears that the substantial increase in extrapolated SAA maintenance requirements in the ISS+ pigs can be attributed largely to increased SAA utilisation for the synthesis of non-protein compounds that are involved in the immune response, such as $\mathrm{GSH}^{(3)}$.

\section{Conclusions and implications}

Repeated injection with increasing amounts of LPS successfully stimulates the immune system and provides a chronic ISS model for studying nutrient utilisation in growing pigs. In the present study ISS per se did not change the SID of dietary AA or the AID of gross energy. However, the observed numerical changes in nutrient digestibility warrant further studies. Metabolic changes associated with ISS reduced the capacity of pigs for maximum whole-body PD at a fixed 
level of energy intake, which most probably contributed to reduced daily SAA requirements for maximum $\mathrm{PD}$. The latter is in spite of ISS-induced increases in SAA requirements for body maintenance functions. The potential impact of ISS, and alternative disease models, on SAA utilisation should be considered when formulating diets for growing-finishing pigs.

\section{Acknowledgements}

The present study was presented in part in Proceedings of the 11th International Symposium on Digestive Physiology of Pigs, Montbrió del Camp, Costa Daurada, Spain, 20-22 May $2009^{(55)}$.

We thank C. L. Zhu, G. Vandervoort and Y. R. Montanholi for technical assistance, and M. Chpak for editorial assistance. The present study was funded in part by the Natural Sciences and Engineering Research Council of Canada, the Ontario Ministry of Agriculture, Food and Rural Affairs, Ontario Pork and Evonik Degussa GmbH (all grants de Lange CFM). The FLIR camera and software were funded from the Canadian Foundation for Innovation and the Ontario Innovation Trust (Miller SP). This research is a publication from the Center for Nutrition Modeling, Department of Animal and Poultry Science, University of Guelph.

The authors' contributions were as follows: A. R. and C. F. M. d. L. designed the study; A. R. conducted the research; A. R. analysed the data; A. R., J. K. H., N. K., S. P. M. and C. F. M. d. L. wrote the paper; C. F. M. d. L. had primary responsibility for the final content. All authors read and approved of the final manuscript.

Author disclosure: A. R., J. K. H., N. K., S. P. M. and C. F. M. d. L. have no conflicts of interest.

\section{References}

1. Reeds PJ \& Jahoor F (2001) The amino acid requirements of disease. Clin Nutr 1, 15-22.

2. Obled C (2003) Amino acid requirements in inflammatory states. Can J Anim Sci 83, 365-373.

3. Breuille D \& Obled C (2000) Cysteine and glutathione in catabolic states. In Proteins, Peptides and Amino Acids in Enteral Nutrition [P Furstand and V Young, editors]. Basel: Karger AG.

4. Fukagawa NK, Ajami AM \& Young VR (1996) Plasma methionine and cysteine kinetics in response to an intravenous glutathione infusion in adult humans. Am J Physiol 270, E209-E214.

5. Malmezat T, Breuille D, Pouyet C, et al. (2000) Methionine transsulfuration is increased during sepsis in rats. Am J Physiol Endocrinol Metab 279, E1391-E1397.

6. Malmezat T, Breuille D, Capitan P, et al. (2000) Glutathione turnover is increased during the acute phase of sepsis in rats. J Nutr 130, 1239-1246.

7. Reid M \& Jahoor F (2001) Glutathione in disease. Curr Opin Clin Nutr Metab Care 4, 65-71.

8. Denko CW, Purser DB \& Johnson RM (1970) Amino acid composition of serum albumin in normal individuals and in patients with rheumatoid arthritis. Clin Chem 16, 54-57.

9. Kluver E, Schulz-Maronde S, Scheid S, et al. (2005) Structure-activity relation of human beta-defensin 3: influence of disulfide bonds and cysteine substitution on antimicrobial activity and cytotoxicity. Biochemistry 44, 9804-9816.

10. Yu YM, Burke JF \& Young VR (1993) A kinetic study of L-2H3-methyl-1-13C-methionine in patients with severe burn injury. I Trauma 35, 1-7.

11. Hang CH, Shi JX, Li JS, et al. (2003) Alterations of intestinal mucosa structure and barrier function following traumatic brain injury in rats. World J Gastroenterol 9, 2776-2781.

12. Jurjus A, Barada K, Khoury N, et al. (2006) Morphological and biochemical alterations in the jejunum following iodoacetamide-induced colitis in rats. Can J Physiol Pharmacol 84, 1191-1203.

13. Faure M, Chone F, Mettraux C, et al. (2007) Threonine utilization for synthesis of acute phase proteins, intestinal proteins, and mucins is increased during sepsis in rats. $J$ Nutr 137, 1802-1807.

14. Hang CH, Shi JX, Sun BW, et al. (2007) Apoptosis and functional changes of dipeptide transporter (PepT1) in the rat small intestine after traumatic brain injury. J Surg Res 137, $53-60$.

15. Nyachoti CM, de Lange CFM \& McBride BW (1998) The effect of flooding dose of phenylalanine on indicators of metabolic status in pigs. Can J Anim Sci 78, 715-718.

16. National Research Council (NRC) (1998) Nutrient Requirements of Swine, 10th ed. Washington, DC: National Academy Press.

17. Wang TC \& Fuller MF (1989) The optimum dietary amino acid pattern for growing pigs. 1. Experiments by amino acid deletion. Br J Nutr 62, 77-89.

18. Deitch EA (1998) Animal models of sepsis and shock: a review and lessons learned. Shock 9, 1-11.

19. Montanholi YR, Odongo NE, Swanson KC, et al. (2008) Application of infrared thermography as an indicator of heat and methane production and its use in the study of skin temperature in response to physiological events in dairy cattle (Bos taurus). J Theor Biol 33, 468-475.

20. Hughes WT, Patterson GG, Thornton D, et al. (1985) Detection of fever with infrared thermometry: a feasibility study. J Infect Dis 152, 301-306.

21. Zhu CL, Rademacher M \& de Lange CF (2005) Increasing dietary pectin level reduces utilization of digestible threonine intake, but not lysine intake, for body protein deposition in growing pigs. J Anim Sci 83, 1044-1053.

22. Low AG (1977) Methods for evaluating feeds for large farm animals. Digestibility at several intestinal sites in pigs. Proc Nutr Soc 36, 189-194.

23. Doumas BT, Watson WA \& Biggs HG (1971) Albumin standards and the measurement of serum albumin with bromcresol green. Clin Chim Acta 31, 87-96.

24. Makimura S \& Suzuki N (1982) Quantitative determination of bovine serum haptoglobin and its elevation in some inflammatory diseases. Nippon Juigaku Zasshi 44, 15-21.

25. Association of Official Analytical Chemists (AOAC) (1997) Official Methods of Analysis, 16th ed. Washington, DC: AOAC.

26. Widyaratne GP \& Zijlstra RT (2007) Nutritional value of wheat and corn distiller's dried grain with solubles: digestibility and digestible contents of energy, amino acids and phosphorus, nutrient excretion and growth performance of grower-finisher pigs. Can J Anim Sci 87, 103-114.

27. Llames CR \& Fontanie J (1994) Determination of amino acids in feeds: collaborative study. J Assoc Off Anal Chem 77, 1362-1366.

28. Stein HH, Fuller MF, Moughan PJ, et al. (2007) Definition of apparent, true, and standardized ileal digestibility of amino acids in pigs. Livestock Sci 109, 282-285. 
29. Jansman AJM, Sminka W, van Leeuwena P, et al. (2002) Evaluation through literature data of the amount and amino acid composition of basal endogenous crude protein at the terminal ileum of pigs. Anim Feed Sci Technol 98 49-60.

30. Robbins KR, Saxton AM \& Southern LL (2006) Estimation of nutrient requirements using broken-line regression analysis. J Anim Sci 84, E155-E165.

31. Baker DH, Becker DE, Norton HW, et al. (1966) Quantitative evaluation of the tryptophan, methionine and lysine needs of adult swine for maintenance. J Nutr 89, 441-447.

32. Burnham KP \& Anderson DR (2002) Information and likelihood theory: a basis for model selection and inference. In Model Selection and Multimodel Inference: A Practical Information-Theoretic Approach, 2nd ed. New York: Springer Science and Business Media, Inc.

33. Gillis AM, Reijmers A, Pluske JR, et al. (2007) Influence of dietary methionine to methionine plus cysteine ratios on nitrogen retention in gilts fed purified diets between 40 and $80 \mathrm{~kg}$ live body weight. Can J Anim Sci 87, 87-92.

34. Langer S \& Fuller MF (2000) Interactions among the branched-chain amino acids and their effects on methionine utilization in growing pigs: effects on nitrogen retention and amino acid utilization. BrJ Nutr 83, 43-48.

35. Dinarello CA (2005) Interleukin-1ß. Crit Care Med 33, S460-S462.

36. Rakhshandeh A \& de Lange CFM (2011) Evaluation of chronic immune system stimulation models in growing pigs. Animal 6, 305-310.

37. Kohl B \& Deutschman CS (2008) The inflammatory response in organ injury. In Perioperative Medicine: Managing for Outcome [MF Newman, LA Fleisher and MP Fink, editors]. Philadelphia, PA: Saunders Elsevier.

38. Breuille D, Arnal M, Rambourdin F, et al. (1998) Sustained modifications of protein metabolism in various tissues in a rat model of long-lasting sepsis. Clin Sci (Lond) 94, 413-423.

39. Jahoor F, Wykes L, Del Rosario M, et al. (1999) Chronic protein undernutrition and an acute inflammatory stimulus elicit different protein kinetic responses in plasma but not in muscle of piglets. J Nutr 129, 693-639.

40. Gabay C \& Kushner I (1999) Acute-phase proteins and other systemic responses to inflammation. $N$ Engl J Med $\mathbf{3 4 0}$, 448-454.

41. Brunkhorst FM, Wegscheider K, Forycki ZF, et al. (2000) Procalcitonin for early diagnosis and differentiation of SIRS, sepsis, severe sepsis, and septic shock. Intensive Care Med 26, S148-S152.

42. Bone RC, Balk RA, Cerra FB, et al. (1992) Definitions for sepsis and organ failure and guidelines for the use of innovative therapies in sepsis. The ACCP/SCCM consensus conference committee. American college of chest Physicians/ Society of critical care medicine. Chest 101, 1644-1655.

43. Baumann H, Prowse KR, Marinkovic S, et al. (1989) Stimulation of hepatic acute phase response by cytokines and glucocorticoids. Ann N Y Acad Sci 557, 280-295.

44. Yamada T (1999) Gastrointestinal system - diseases. In Textbook of Gastroenterology, 3rd ed. [T Yamada, DH Alpers, L Laine, C Owyang and DW Powell, editors]. Philadelphia, PA: Lippincott Williams and Wilkins.
45. Fuller MF (1988) Methods of protein evaluation for nonruminants. In World Animal Science B4. Feed Science [ER Orskov, editor]. Amsterdam: Elsevier.

46. Donkoh A, Moughan PJ \& Smith WC (1994) Comparison of the slaughter method and simple T-piece cannulation of the terminal ileum for determining ileal amino acid digestibility in meat and bone meal for the growing pig. Anim Feed Sci Technol 49, 43-56.

47. Badawy AM (1964) Change in the protein and non-protein nitrogen in digesta of the sheep. In The Role of Gastrointestinal Tract in Protein Metabolism [HN Munro, editor]. Oxford: Blackwell.

48. Barker IK (1974) The relationship of abnormal mucosal microtopography with distribution of trichostrongylus colubriformis in the small intestines of lambs. Int J Parasitol $\mathbf{4}$, $153-163$.

49. Williams NH, Stahly TS \& Zimmerman DR (1997) Effect of chronic immune system activation on body nitrogen retention, partial efficiency of lysine utilization, and lysine needs of pigs. J Anim Sci 75, 2472-2480.

50. Zoric M, Arvidsson A, Melin L, et al. (2003) The significance of an exposure to Actinobacillus pleuropneumoniae for the fecal coliform microflora and the digestibility of nutrients in specific pathogen-free pigs. Intern J Appl Res Vet Med 1, $4-11$.

51. Nyachoti CM, de Lange CFM, McBride BW, et al. (1997) Significance of endogenous gut nitrogen losses in the nutrition of growing pigs: a review. Can J Anim Sci 77, 149-163.

52. Mohn S, Gillis AM, Moughan PJ, et al. (2000) Influence of dietary lysine and energy intakes on body protein deposition and lysine utilization in the growing pig. J Anim Sci 78, 1510-1509.

53. Lecker SH, Goldberg AL \& Mitch WE (2006) Protein degradation by the ubiquitin-proteasome pathway in normal and disease states. J Am Soc Nephrol 17, 1807-1819.

54. Fuller MF, McWilliam R, Wang TC, et al. (1989) The optimum dietary amino acid pattern for growing pigs 2 . Requirements for maintenance and for tissue protein accretion. Br J Nutr 62, 255-267.

55. Rakhshandeh A, Htoo JK \& de Lange CFM (2010) Immune system stimulation of growing pigs does not alter apparent ileal amino acid digestibility but reduces the ratio between whole body nitrogen and sulfur retention. Livest Sci 134, $21-23$.

56. Larsson J, Liljedahl SO, Martensson J, et al. (1982) Urinary excretion of sulfur amino acids and sulfur metabolites in burned patients receiving parenteral nutrition. J Trauma 22, 656-663.

57. Hunter EAL, Meakins $T$ \& Grimble RF (1993) Effects of glycine and arginine supplementation on the metabolic response to tumour necrosis factor in rats fed low-protein diets. Proc Nutr Soc 52, 90A.

58. Hou C, Wykes LJ \& Hoffer LJ (2003) Urinary sulfur excretion and the nitrogen/sulfur balance ratio reveal nonprotein sulfur amino acid retention in piglets. J Nutr 133, 766-772.

59. Malmezat T, Breuille D, Pouyet C, et al. (1998) Metabolism of cysteine is modified during the acute phase of sepsis in rats. J Nutr 128, 97-105. 